\title{
EKSPLORASI LIMBAH KACA PADA PROSES FINISHING GELASIR BODI KERAMIK
}

\author{
Arif Suharson *)
}

\begin{abstract}
Currently, industrial waste is an important issue since it is associated to global warming. Glass is used in such kinds of products as perfume and beverage bottles and lamps. Glass is preferred due to its advantage of transparency. However, glass also has disadvantage of fracture. More importantly, glass is non-biodegradable substance and therefore it contaminates the earth. Thus, besides plastic waste, glass waste is a serious issue and deserves comprehensive treatment to prevent natural sustainability. It takes one billion years to have the glass degradable naturally,

The researcher is interested in researching glass waste. It is expected that the study will contribute to solve the problem of natural balance. Glass waste is an alternative for ceramic glazing. This study employs experimental method with scientifically accountable structured and recorded exploration of data through experiments of glass waste for effective and efficient glazing material. It is expected that this research will contribute to the development of science among traditional ceramic artisans and other ceramic producers to result in creative and innovative glass-based media of expression.

It is also expected that this study will motivate the society to have better concern on glass waste as well as excite creativity and innovation resulting in new attractive design of glasswaste glazed ceramics with higher competitiveness in the global market.
\end{abstract}

Key words: glass waste, glazing, ceramic

\section{PENDAHULUAN}

Melihat perkembangan ilmu keramik pada saat ini telah banyak perubahan, dimana bahan tanah liat tidak hanya dibuat sebagai media membuat produk rumah tangga tetapi juga sudah pada tahap pemenuhan kebutuhan dunia industri. Pembuatan produk keramik juga mulai dikembangkan pada pemenuhan kebutuhan fungsional praktis dan kebutuhan seni sebagai media ekspresi dalam dunia seni rupa. Akan tetapi bahan-bahan untuk proses gelasir ini masih banyak didatangkan dari luar negeri yang harganya terus melonjak naik. Hal ini berpengaruh besar pada kelangsungan produksi keramik stoneware di Indonesia. Dimana juga belum adanya standarisasi warna bahan finishing gelasir yang pasti dan untuk dijadikan pedoman kontinyu terkait komposisi keajegan warnanya. Dapat dikatakan unsur bahan gelasir sama tetapi jika diambil dari daerah atau wilayah tempat penggaliannya yang berbeda, maka kandungannya menjadi berbeda pula. Sehingga untuk mendapatkan hasil yang sama harus dilakukan pengujian komposisi bahannya sebelum diterapkan pada produk keramik.

\footnotetext{
* Arif Suharson (arifkeramos@yahoo.com), Staf Pengajar Program studi Kriya Seni, Jurusan Kriya, Fakultas Seni Rupa, Institut Seni Indonesia Yogyakarta.
} 
Sifat keramik sangat ditentukan oleh struktur kristal, komposisi kimia dan mineral bawaannya. Oleh karena itu sifat keramik juga tergantung pada lingkungan geologi dimana bahan diperoleh. Gelasir merupakan lapisan gelas yang dapat berupa matt (tidak mengkilap), ataupun licin dan dapat pula berupa lapisan mengkilap dengan suhu antara $1050^{\circ} \mathrm{C}-1250^{\circ} \mathrm{C}$. Jadi merupakan suatu macam gelas khusus yang diformulasikan secara kimia agar dapat melekat dan menjadi keras pada permukaan tanah liat, atau melebur ke dalam bodi tanah liat bila dibakar (Ambar Astuti, 2009:77). Unsur gelas atau silica inilah yang digunakan sebagai salah satu bahan utama dalam proses finishing gelasir. Melihat kandungan limbah kaca yang terdapat unsur silica timbul keinginan untuk melakukan percobaan-percobaan ilmiah menggunakan limbah kaca sebagai alternative untuk menggelasir produk keramik.

Pemakaain produk-produk pemenuhan kebutuhan hidup manusia juga masih banyak yang menggunakan unsur kaca atau gelas. Kita bisa melihat botol kaca untuk minuman, parfum, lampu dan masih banyak lagi produk yang menggunakan material kaca yang dinilai memiliki keunggulan karena kualitas transparannya. Tetapi kaca juga memiliki banyak kelemahan yang riskan terhadap benturan dan kaca merupakan penyuplai limbah yang tidak bisa dimusnahkan. Limbah kaca merupakan bahan yang tidak bisa diurai oleh tanah. Sehingga keberadaan limbah kaca menjadi masalah tersendiri yang perlu mendapatkan perhatian khusus selain limbah plastik yang mulai mengganggu keseimbangan lingkungan alam. Kaca membutuhkan waktu 1.000.000 tahun untuk dapat diurai di alam, sedangkan data statistik tentang limbah kaca di Indonesia pada tahun 2003-2008 di 26 kota-kota besar menyumbang limbah kaca sebesar 0,7 ton pertahun (Suyoto, 2008). Memang terlihat angka yang kecil tetapi mempunyai efek yang besar terhadap keseimbangan alam kita.
Hal inilah yang perlu dikaji untuk dilakukan penelitian dengan metode eksperimen dan eksplorasi secara terdata dan terstruktur untuk menemukan jawaban yang dapat dipertanggungjawabkan secara ilmiah. Limbah kaca dapat diekplorasikan untuk kembali dimanfaatkan sebagai alternatif finishing pada bodi keramik yang efisien dan efektif yang dapat diaplikasikan pada bahan tanah liat earthanware dan stoneware. Dengan demikian penelitian ini diharapkan akan membantu para pengrajin keramik tradisional kita dan para pelaku keramik sebagai salah satu alternatif finishing gelasir bodi keramik yang efektifefisien serta sebagai media ekspresi seni yang kreatif dan inovatif.

\section{HASIL DAN PEMBAHASAN}

Penelitian ini berusaha mencari dan memberikan penjelasan secara kualitatif, sehingga metode yang digunakan adalah kualitatif. Penelitian kualitatif sering berupa studi tentang makna yang terkandung dalam obyek penelitian, dapat pula berupa studi kasus atau multi kasus dalam penelitian lapangan. Melalui penelitian ini secara internal adalah sebagai salah satu telaah lingkup bidang ilmu seni rupa, khususnya seni kriya keramik yang memanfaatkan limbah kaca untuk alternatif finishing bodi keramik. Secara eksternal dapat dijadikan motivasi dan meningkatkan kreativitas bagi para keramikus Indonesia untuk tidak bergantung pada bahan-bahan kimia import dan dapat memanfaatkan sumber daya alam yang ada disekitar kita.

Hasilnya dapat dijadikan informasi dan referensi tentang seni keramik akademis maupun non-akademis, serta sebagai sumbangan bagi negara, dalam usaha mengatasi permasalahan sampah atau limbah industri yang tidak produktif menjadi bermanfaat. Penelitian yang bersifat penelitian eksperimen ini dilakukan untuk mengetahui hal-hal yang bersifat baru dan menemukan sesuatu yang berbeda dari yang sudah pernah ada. Dalam penelitian ini dilakukan tahap-tahap eksperimen untuk 
mencari bahan-bahan limbah kaca yang dapat diaplikasikan sebagai bahan untuk finishing gelasir pada bodi keramik.

\section{Jenis bahan kaca untuk gelasir}

Keberadaan limbah industri rumah tangga khususnya yang diakibatkan oleh limbah dari kemasan minuman atau makanan, baik yang berbahan, plastik, aluminium foil, dan kaca perlu mendapatkan perhatian khusus oleh kita. Jika mencermati limbah tersebut terutama kaca yang sangat sulit diurai oleh alam, tentu kita sebagai manusia penjaga kelestarian alam ini akan berpikir untuk mencari solusi agar limbah kaca dapat dimanfaatkan sebagai bahan alternative yang bisa digunakan kembali. Karena kaca adalah unsur bahan yang saat ini sudah menjadi salah satu penyebab adanya pemanasan global. Hal tersebut ditengarai oleh banyaknya emisi kaca yang digunakan manusia untuk berbagai kebutuhan seperti pelengkap membuat rumah dengan kaca. Akan tetapi berdampak serius terhadap perubahan iklim dan kesimbangan alam kita.

Kemudahan dan daya guna kaca yang sangat fleksibel harus disikapi secara baik, agar limbah kaca dapat dipikirkan kembali fungsi dan kegunaannya dengan melakukan terobosan-terobosan baru pemanfaatan limbahnya untuk kebaikan alam kita. Yang demikian itu akan membuat keberlangsungan hidup manusia dan generasi penerus juga akan ikut menikmati kehidupan yang terus baik yang berdampak pada kesehatan manusianya. Salah satu terobosan tersebut seperti yang sedang kami kembangkan dengan memanfaatkan limbah kaca menjadi bahan alternative gelasir pada bodi keramik. Dengan penelitian yang kami lakukan tersebut diharapkan memberikan edukasi bagi para keramikus dan orang lain untuk memanfaatkan limbah kaca menjadi lebih memiliki nilai dan ikut menjaga keseimbangan lingkungan alam bersama.

Gelasir merupakan lapisan gelas yang didalamnya mengandung unsur gelas atau dalam ilmu kimia mengandung unsur silica (Si) dengan jumlah kandungan yang berbeda. Unsur gelas atau silica inilah yang digunakan sebagai salah satu bahan utama dalam proses finishing gelasir. Glass Former /Silica (SiO2) merupakan salah satu bahan yang penting dalam semua bahan-bahan keramik, baik untuk mase maupun untuk gelasir yaitu sebagai pembentuk gelas. Bahan pembentuk gelas tersedia dari pasir silica, yang mengandung 99,5\% Silica, sisanya terdiri dari Calcium Carbonate atau Chrome. Kwarsa adalah suatu bentuk lain dari batuan silica yang $100 \%$ murni. Silica atau kwarsa biasanya bergabung dengan oksida-oksida lain yan disebut Silicates. Contoh gabungan tersebut misalnya dalam kaolin, china stone, feldspat, nepheline syenite, bentonite, lepidolite, petalite, spodumene, juga dalam mineral-mineral lainnya (Astuti, 2007:28).

Dalam penelitian ini unsur-unsur kaca yang diterapkan diambil dari berbagai kaca yang sudah merupakan limbah dari kaca botol bekas parfum, minuman, atau makanan, kaca untuk jendela atau pintu, dan kaca neon. Bahan-bahan limbah kaca yang dimaksud tersebut sangat mudah didapatkan disekitar lingkungan kita. Bahkan bahan-bahan ini sangat mudah didapatkan di tempat-tempat pembuangan sampah umum. Bahan-bahan limbah dari botol-botol kaca juga dijual bebas dengan harga yang murah di tempat-tempat pengepul sampah atau sering disebut tempat pengumpul rongsokan. Kaca-kaca tersebut oleh tim peneliti dibuat menjadi unsur tepung dan menjadi bahan gelasir pengganti TSG. Jadi eksperimen yang dilakukan adalah menjadikan limbah kaca sebagai penggati gelasir yang sering digunakan yaitu TSG.

\section{Alur Penelitian}

Penelitian ini merupakan penelitian ekperimen yang di dalam kegiatan penelitiannya dilakukan percobaanpercobaan tercatat untuk memperoleh hasil yang diinginkan. Untuk memperlancar kegiatan tersebut, peneliti membuat 
langkah-langkah praktis dengan membuat alur kerja penelitian sebagai berikut:

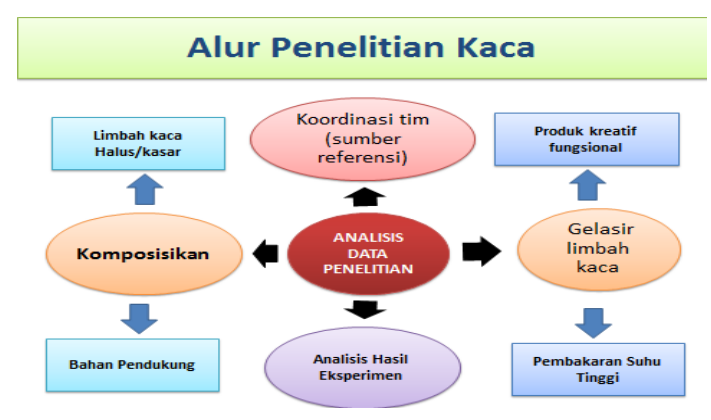

Output dari penelitian ini akan melihat apakah lapisan gelas kaca yang sering disebut gelasir dari bahan limbah kaca dapat menempel baik pada bodi dan dapat digunakan sebagai ganti TSG. Setelah melakukan pencarian data warna yang terdapat pada unsur kaca, tim peneliti menemukan beberapa warna dari kaca yang mudah didapatkan disekitar kita terdiri dari:

- Warna hijau tua yang banyak dijumpai pada botol minuman energi, botol kecap, dan botol beralkohol

- Warna trasparan atau bening dapat dijumpai seperti pada botol minuman energy, lampu neon/dop, dan parfum

- Warna biru dapat ditemukan pada warna botol lampu dan kaca untuk jendela/pintu.

- Warna coklat tua dapat ditemukan pada minuman energy dan dan minuman beralkohol.

Dalam penelitian ini dilakukan uji bahan limbah kaca dengan mencampur warna pigmen gelasir dan tanpa mencampur pigmen warna gelasir dimana warna diperoleh langsung dari warna limbah kaca. Penggunaan warna pigmen gelasir hanya untuk limbah kaca yang tidak memiliki warna atau kaca yang bening. Proses eksperimen dengan menyiapkan seluruh bahan limbah kaca dan dibuat dalam 4 kategori warna 3 tingkat kehalusan ukuran kaca. Tujuan dari penggolongan tersebut agar peneliti memperoleh karakter dari masing-masing kaca dan hasil warna dari bodi yang dapat dijadikan pedoman untuk membuat standar ukuran atau timbangan yang ideal. Hal ini dilakukan agar eksperimen memperoleh nilai validitas yang baik tentang titik lebur kaca dan ukuran titik lebur yang paling sesuai.

Untuk memastikan hasil eksperimen tersebut peneliti membuat percobaan pertama yaitu membakar kaca asli dengan tidak mencapur bahan pendukung apapun. Kaca yang sudah dihaluskan diletakkan pada bodi keramik yang dibiscuit dan sudah diwarna putih dengan posisi datar. Juga pada bodi keramik sesuai warna tanah yang digunakan dalam pembuatan produk. Limbah kaca dicoba dibakar pada suhu $1000^{\circ}$ $\mathrm{C}-1100^{\circ} \mathrm{C}$. Mengapa dibakar disuhu tersebut karena menurut tim kreatif warna gelasir dari perusahaan Burat Kriasta (Mbak Tin 36 th: wawancara pada tanggal 3 Agustus 2016) yang sudah biasa membakar kaca mengatakan titik lebur kaca pada suhu tersebut $1050^{\circ} \mathrm{C}$. Dari keterangan tersebut peneliti ingin membuat titik aman dan melakukan pencermatan pada titik lebur kaca tersebut dengan suhu $1000^{\circ} \mathrm{C}-1100^{\circ} \mathrm{C}$. Jadi dapat diambil kesimpulan bahwa tidak mungkin kaca diterapkan untuk produk yang terbuat dari tanah earthenware yang tanahnya matang di bawah $1000^{\circ} \mathrm{C}$. Karena biasanya tanah erathanware sudah matang pada suhu maksimal $900^{\circ} \mathrm{C}$. Melihat kenyataan tersebut akhirnya penelitian kami fokuskan untuk tanah stoneware karena titik lebur kaca pada suhu $1000^{\circ} \mathrm{C}-1100^{\circ} \mathrm{C}$. Dan tanah stoneware yang memiliki ketahanan titik lebur sampai pada suhu $1250^{\circ} \mathrm{C}$.

Pada hasil eksperimen yang telah dilakukan (lihat lampiran) kita bisa melihat hasil warnanya. Dimana keramik dan limbah kaca dibakar bersamaan dengan suhu $1100^{\circ}$ $\mathrm{C}$ telah menunjukkan bahwa tidak ada perubahan warna yang signifikan. Akan tetapi terjadi karakter khas kaca yang dimana kaca dengan pecahan kasar akan membentuk karakter pecah atau sering disebut cracking atau pecah seribu. Karakter ini terlihat menarik dan memiliki nilai value tersendiri dalam produk keramik. Hasil limbah kaca juga melekat bagus dalam bodi 
keramik yang dibakar dalam keadaan datar dan cekung. Dapat diambil kesimpulan bahwa eksperimen kaca dalam bodi datar atau cekung dapat dikatakan berhasil melekat baik pada bodi keramik dan memiliki efek yang baik pula.

Percobaan gelasir dengan limbah kaca yang selanjutnya dilakukan pada bodi keramik yang berbentuk 3 dimensional atau tegak lurus. Apakah lapisan kaca yaitu gelasir dapat menempel baik juga pada bodi keramiknya seperti eksperimen di atas?. Kaca yang digunakan masih sama dengan warna yang telah dicobakan pada eksperimen sebelumnya. Bedanya kaca dibuat agak lebih halus agar dapat dioleskan pada bodi keramik. Kaca yang paling mudah dihancurkan adalah kaca yang terbuat dari neon. Dan kaca neon dapat ditambah dengan bahan warna oksidasi gelasir. Setelah kaca berhasil dibuat dalam bentuk tepung, langkah selanjutnya melarutkan kaca dalam air dan mengkuaskan pada bodi produk keramik 3 dimensional yang posisinya berdiri vertikal. Setelah bodi diberi lapisan limbah kaca kemudian dimasukkan tungku pembakaran dan dibakar pada suhu $1100^{\circ} \mathrm{C}$

Semua limbah kaca dapat dikatakan bisa menjadai alternative bahan gelasir, tetapi dari segi kemudahan teknis pengolahan kaca, peneliti dapat merekomendasikan bahwa bahan kaca dari limbah lampu neon atau bola adalah bahan yang paling mudah proses pengerjaannya. Limbah kaca lampu tersebut adalah jenis limbah kaca yang memiliki tingkat ketipisan yang baik dan bahan kaca yang digunakan sangat lunak. Sehingga mudah dipecah dan dibuat butiran lembutnya untuk dijadikan bahan gelasir. Kemudahan proses tersebut sangat membantu peneliti untuk membuat dalam jumlah banyak dan kemudian disaring dengan mess 80-100 agar bahan limbah kaca dapat dibuat menjadi menyatu/homogen dengan bahan pewarna gelasir atau bahan pendukung gelasir lainnya. Jadi dapat disimpulkan bahwa bahan lampu neon menjadi salah satu bahan penting dan paling mudah prosesnya untuk membuat finishing gelasir pada bodi produk keramik yang memiliki bidang berdiri atau tegak dengan dicampur pigmen gelasir.

Limbah kaca yang sudah siap untuk diaplikasikan dalam finishing gelasir pada keramik 3 dimensi dibuat dalam dua komposisi bahan yang berbeda untuk mengetahui hasil tingkat daya lekat limbah kaca pada bodi keramik. Proses pembuatan komposisi limbah kaca sebagai alternative bahan gelasir dalam penelitian ini menggunakan beberapa teknik pengkomposisian bahan. Komposisi teknis tersebut adalah :

1. Limbah kaca langsung dicampurkan dengan bahan pigmen warna yang dilarutkan dengan air, dan kemudian campuran tersebut dikuaskan pada bodi keramik

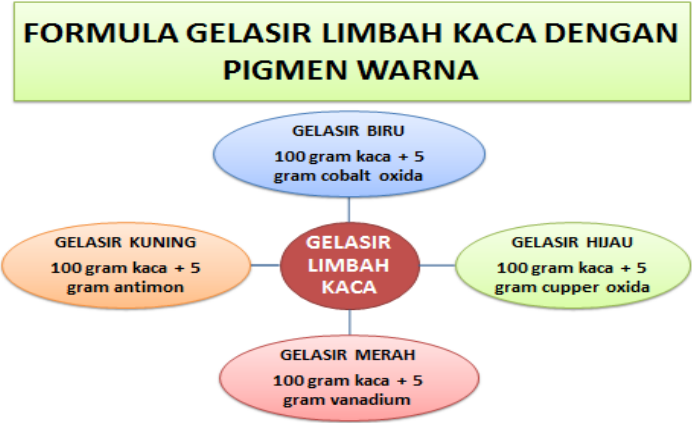

2. Limbah kaca dibuat dalam bentuk engobe yaitu dengan mencampur limbah kaca dengan pigmen warna dan tanah plastis dicampur dengan air. Larutan engobe yang sudah jadi kemudian dikuaskan pada bodi keramik.

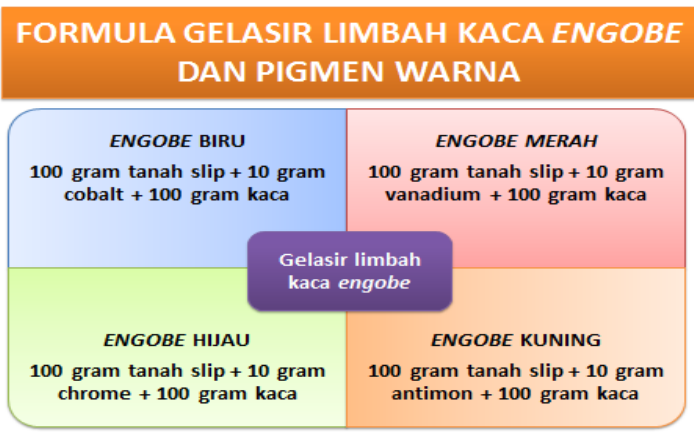

Hasil komposisi tersebut kemudian diterapkan pada produk fungsional dengan 
cara dikuaskan dan dibakar dengan suhu $1100^{\circ}$ C. Untuk mengetahui hasil yang maksimal dan supaya dapat dilihat perbedaann kekuatan gelasirnya, maka teknik penyusunan produk dalam pembakaran dibuat dalam 3 tingkatan di 3 bagian yang berbeda. Yaitu dibagian atas, tengah, dan bawah dalam susunan produk di tungku pembakaran. Pada tiap bagian tersebut dibagi juga dengan 3 tempat yang berbeda yaitu di samping kanan, tengah, dan samping kiri. Setelah dibakar gelasir, kemudian dilakukan analisis pada hasil gelasir dengan 2 komposisi tersebut dan teknik penyusunan di dalam tungku.

Kesimpulan yang dapat diambil bahwa keramik yang diberi gelasir limbah kaca dengan komposisi engobe lebih baik hasil gelasirnya. Limbah kaca tidak cepat meluncur dan dapat menempel pada bodi keramik dengan baik pula. Kelemahannya hasil warna gelasir belum dapat merata secara maksimal. Tetapi alternative gelasir engobe dengan limbah kaca neon sangat mudah dibuat dengan bahan pendukung warna pigmen. Hal ini dapat disebabkan karena tingkat keenceran engobe atau tingkat ketebalan lapisan engobe yang ada pada bodi keramik. Sehingga perlu ada pengujian berulang untuk dapat melihat tingkat keberhasilan gelasir pada bodi keramik.

\section{PENUTUP}

Penelitian pemanfaatan limbah kaca dengan metode eksperimen telah dapat dilaksanakan dan didapatkan data penelitian yang mendukung validitas hasil eksperimennya. Dengan data yang telah diperoleh dari penelitian awal ini, sangat dibutuhkan adanya tindaklanjut yang terprogram dan terstruktur dengan pengujian-pengujian lanjutan. Sehingga validitas hasil ilmiahnya dapat lebih dipertanggungjawabkan dengan uji laboratorium yang dapat mengetahui secara tepat perhitungan unsur kimiawinya. Unsur kimiawi dengan perhitungan prosentase dan masanya sangat diperlukan untuk menentukan hasil pencapaian yang maksimal sebagai pedoman ilmiah yang dapat diacu oleh pelaku keramik. Metode ini akan mampu meningkatkan mutu, membuat gelasir bersuhu terukur, dan meningkatkan daya kreasi pengrajin dalam membuat diversifikasi finishing gelasir dengan pemanfaatan limbah kaca dan tidak bergantung pada bahan gelasir import.

Keuntungan lain yang dapat kita lakukan demi keberlangsungan hidup orang banyak dan keseimbangan alam yaitu dengan mengurangi limbah kaca yang sulit diurai oleh alam dan memanfaatkan limbah kaca menjadi lebih bermanfaat bagi dunia keramik. Hal tersebut menjadi semangat kolektif yang ditumbuhkan dari kesadaran pribadi-pribadi untuk terus berinovasi dan akan tergerak untuk melakukan penelitianpenelitian eksperimental yang lain terkait dengan limbah industry dan pemanfaatan bagi lingkungan. Terutama penelitianpenelitian dibidang keramik yang terus mengalami perkembangan dan dibutuhkan pengembanagan yang dapat dimanfaatkan oleh masyarakat menghadapi persaingan global di era modern.

Hasil dari kegiatan penelitian eksperimen yang telah dilakukan akan menjadi pemicu semangat jiwa kreativitas para pelaku keramik khususnya seniman tradisional untuk lebih mampu meningkatkan ilmu pengetahuan terbarukan, sebagai referensi menciptakan produk-produk kreatif, melakukan inovasi finishing produk, sehingga akan mampu meningkatkan mutu hasil produksinya. Hasil penelitian yang sudah kami kerjakan juga akan dapat dijadikan alternative finishing yang efektif dan efisien dengan pemanfaatn limbah kaca yang baik. Hasil tersebut tampak pada keramik dengan bidang cekung sangat baik diberi aksen cracking yang menggunakan limbah kaca berwarna tanpa mencampur bahan pendukung lainnya.

Gelasir dengan teknik engobe dimana limbah kaca yang memiliki warna bening/tidak berwarna seperti neon dapat dicampur dengan warna pigmen 
dikomposisikan dengan tanah plastis. Hasil tersebut dapat menjadi finishing gelasir yang dapat diterapkan pada bodi produk keramik, baik yang berbentuk cekung, cembung, dan berdiri tegak lurus. Dengan hasil penelitian eksperimen limbah kaca sebagai alternative finishing gelasir dapat dilakukan dengan hasil yang baik, tetapi dibutuhkan tindaklanjut penyempurnaan penelitian lanjutan. Agar limbah kaca dapat diekplorasi kembali untuk dijadikan gelasir yang memiliki pedoman ilmiah dan limbah kaca dapat dikurangi dengan pemanfaatanpemanfaatan yang lebih bijaksana demi kelangsungan hidup manusia di masa mendatang.

\section{DAFTAR PUSTAKA}

Astuti, Ambar, 2008, Keramik: Bahan Cara Pengerjaan Gelasir, Arindo Nusa Media, Yogyakarta.

Proses Pembuatannya, Jurusan
Kriya, Fakultas Seni Rupa ISI
Yogyakarta.

Douglas, R.W, 1972, A History of Glassmaking, GT Foulis \& Co. Ltd. London

Gay, L. R. 1981, Educational Research: Competencies for Anlysis and Application. London: Prentice-Hall International (UK) Itd.

Hoge, Elisabeth dan Horn, Jane, 1989, Keramik : Lengkap dengan Teknik dan Rancangannya, Semarang: Dahara Prize.

Isaac, S. dan William B. M. 1977, Handbook in Reasearch and Evaluation: For Education and the Behavioral Sciences. First edition. San Diego, CA: EdiTS

Kerlinger. 2006, Asas-asas Penelitian Behavioral Edisi Ketiga, Yogyakarta: Gajah Mada University Press. Kusnadi., Peran Seni Kerajinan (Tradisional dan Baru) Dalam Pembangunan, (Majalah Seni XVII, 1983).
Mc Millan, J.H. dan Schumacher, S. 2010, Research in Education (Evidence Based Inquiry) Seventh Edition, London: Pearson.

Moleong, Lexy J, 2004, Metodologi Penelitian Kualitatif, Penerbit PT Remaja Rosdakarya, Bandung

Mucthar, But, 1991, "Daya Cipta Bidang Kriya" dalam SENI, Jurnal Pengetahuan dan Penciptaan Seni, VII/01, BP ISI Yogyakarta

Nasution, 2005, Buku Penuntun Membuat Tesis, Skripsi, Disertasi, Penerbit Bumi Aksara, Jakarta.

Nawawi, Hadari, 1990, Metode Penelitian Bidang Sosial, Gadjah Mada University Press, Yogyakarta.

Raharjo, Timbul, 2009, Historis Desa

Gerabah Kasongan, Yogyakarta : Program Pascasarjana ISI Yogyakarta.

Soedarsono, R.M, 1999, Metodologi Penelitian Seni Rupa dan Pertunjukan, Masyarakat Seni Pertunjukan Seni Indonesia, Bandung

Soedarso SP., 2006, Trilogi Seni Penciptaan, Eksistensi, Dan Kegunaan Seni, Yogyakarta: Badan Penerbit Institusi Seni Indonesia Yogyakarta.

Suyoto, Bagong, 2008, Fenomena Gerakan Mengolah Sampah, PT. Prima Infosarana Media, Jakarta 
HASIL EKPERIMEN GELASIR LIMBAH KACA

(tanpa dicampur bahan pendukung lainnya)

\begin{tabular}{|l|l|l|}
\hline Pecahan Kaca & Warna Kaca & $\begin{array}{c}\text { Hasil Pembakaran limbah kaca } \\
\text { pada bodi asli tanah }\end{array}$ \\
\hline & Bem n mning & \\
\hline & Hijau & \\
\hline & Biru & \\
\hline
\end{tabular}




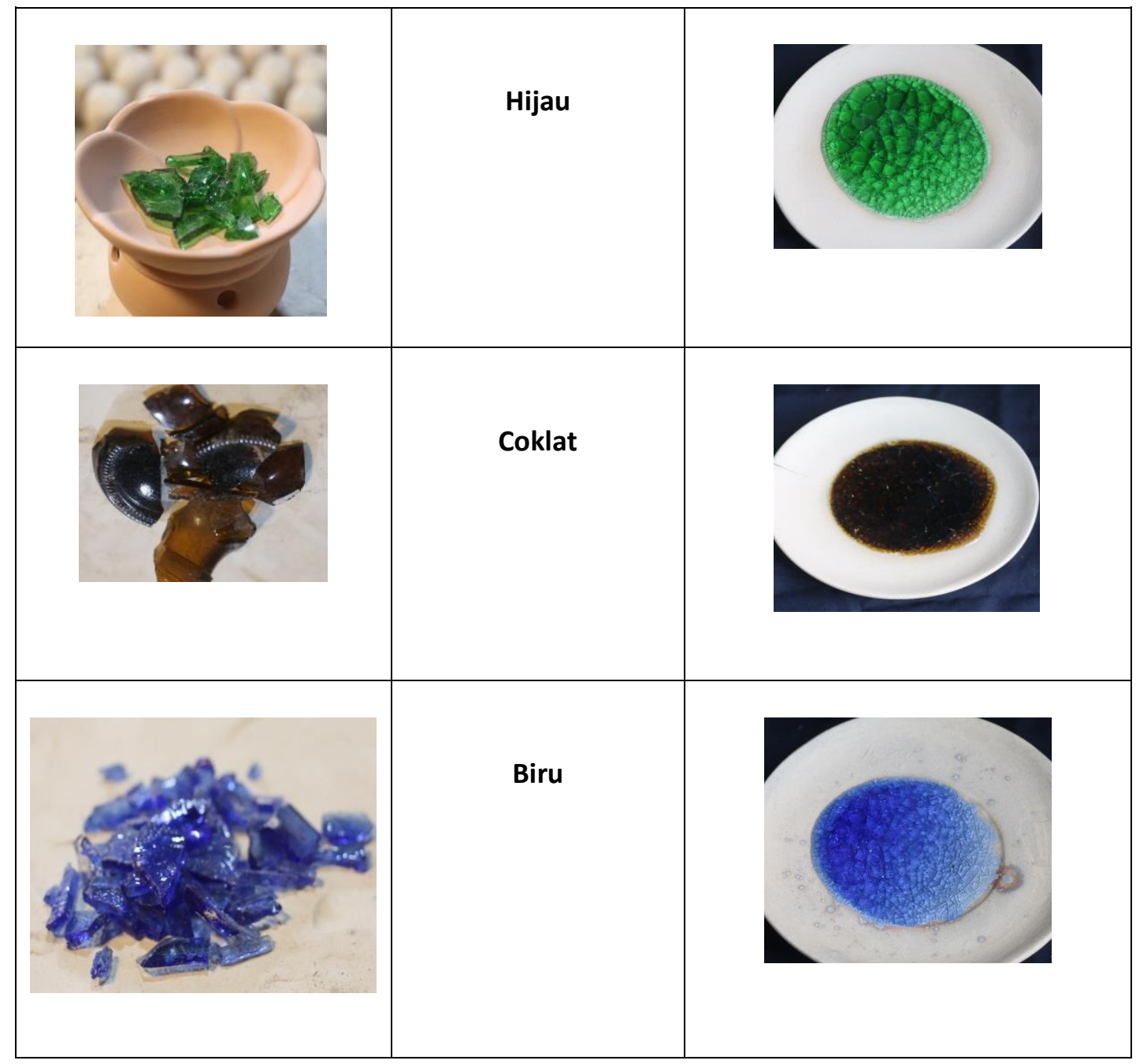

Gambar 1. Gelasir Limbah Kaca dicampur bahan pendukung lainnya. 


\section{HASIL PENELITIAN GELASIR LIMBAH KACA PADA PRODUK FUNGSIONAL}
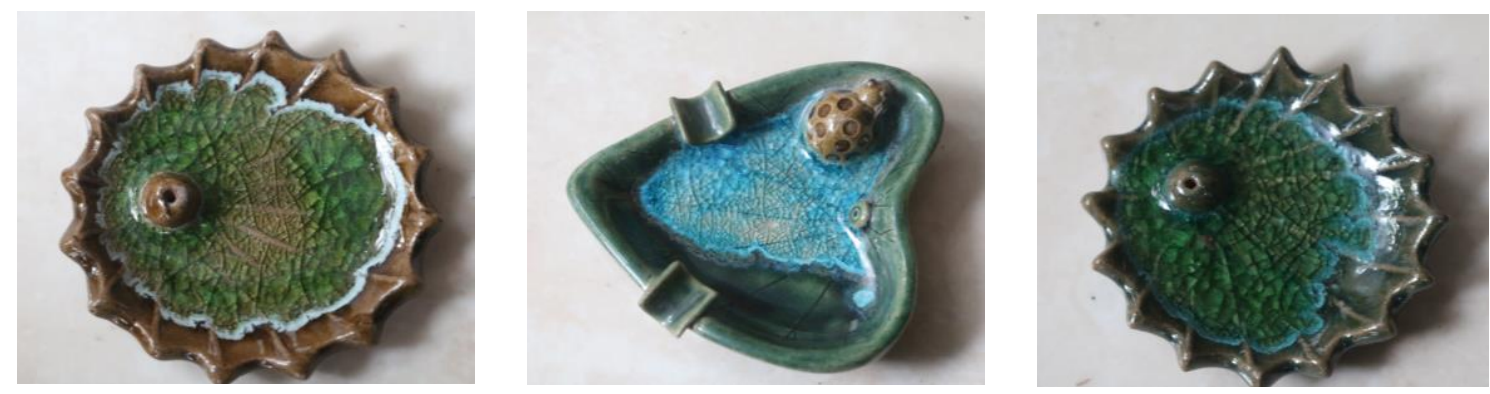

Gambar 2. Gelasir Limbah Kaca tanpa mencampur bahan pendukung lainnya.
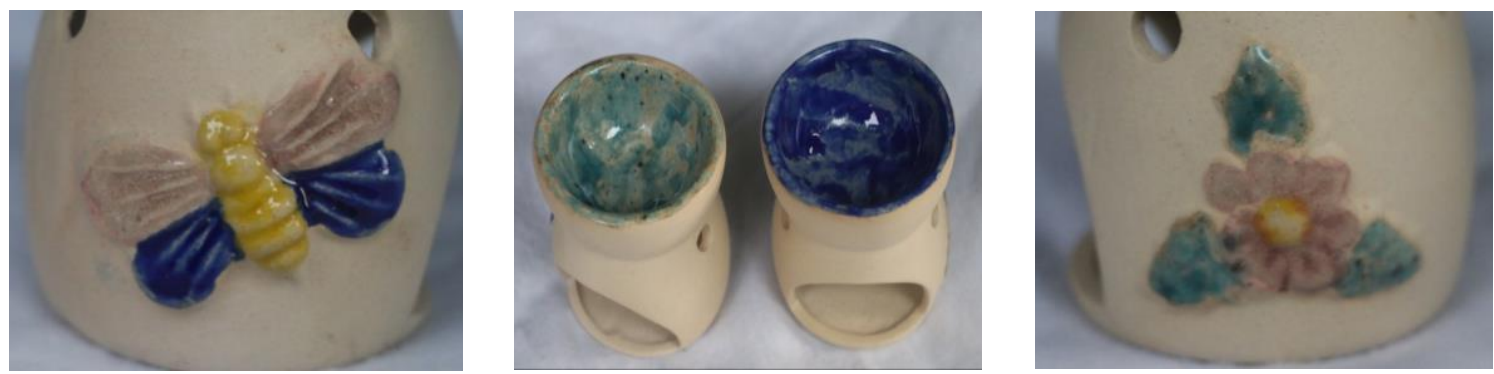

Gambar 3. Gelasir Limbah Kaca dengan pigmen warna
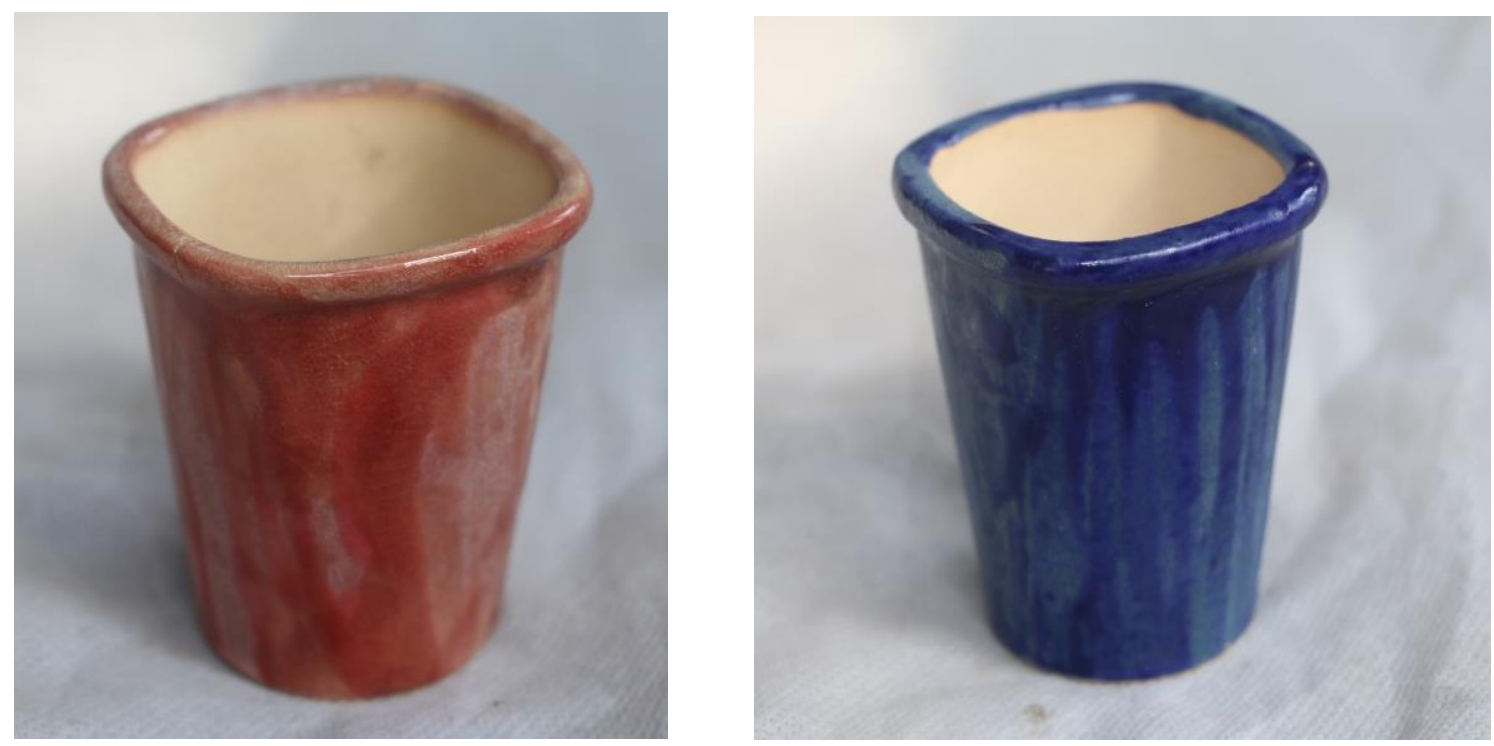

Gambar 4. Gelasir Limbah Kaca dengan pigmen warna dan engobe 